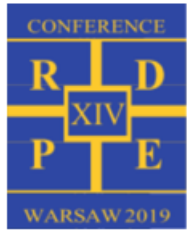

\title{
Selecting optimal conditions for the turbine warm and hot start-up
}

\author{
Andrzej Rusin ${ }^{1 *}$, Grzegorz Nowak ${ }^{2}$,Henryk Łukowicz ${ }^{3}$,Wojciech Kosman ${ }^{4}$, Tadeusz Chmielniak ${ }^{5}$, \\ 1,23,4,5 Silesian U niversity of Technology, Institute of Power Engineering and Turbomachinery, Konarskiego 18, 44-100 Gliwice, \\ Poland, andrzej.rusin@ polsl.pl, grzegorz.nowak@ polsl.pl, henryk.lukowicz@ polsl.pl, wojciech.kosman@ polsl.pl, \\ tadeusz.chmielniak@polsl.pl
}

\begin{abstract}
The changing role of coal-fired power units which are now used more and more often as sources balancing the demand for electricity in the power system calls for a change in the character of their operation. They have to be able to respond appropriately to rapid and substantial variations in loads and they must have the capacity for shortening the start-up time, especially after a few or several hours of downtime. The paper presents an analysis of changes in thermal states in the turbine main elements after short downtime periods and shows the possibilities and consequences of the turbine fast start-up from such states. Optimal warm and hot start-up characteristics are developed. Detailed del iberations are devoted to el ements of $200 \mathrm{M} \mathrm{W}$ turbines, most of which are and will be used as flexible sources of electricity generation in the power system.
\end{abstract}

\section{Introduction}

The changing structure of power systems and the new role of coal-fired power units which more and more often now act as sources balancing the demand for electricity call for a change in the character of their operation [1]. This is due to the increasing share of renewable energy sources, wind power in particular, in the current energy mix. The present share of different kinds of power plants in the total production of el ectricity in Poland is presented in Fig. 1.

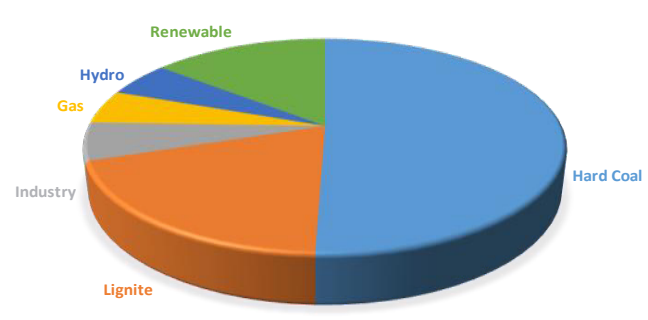

Fig. 1. Percentage share of individual groups of power generation in electricity production in Poland - July 2019

A s it can be seen, the lion @ share in energy generation falls to coal-fired power plants, which at the same time have to increase electricity production if no wind energy is available. This means that coal-fired power units have to be able to respond appropriately to rapid and substantial variations in loads and they must have the capacity for shortening the start-up time, especially after a few or several hours of downtime. Considering that these requirements increase the thermal load of individual elements of power units and taking account of the relatively long service life, new and optimal operating conditions have to be determined to ensure adequate safety of the power plant future operation in the new regime [2]. The new conditions should make it possible to improve the operation flexibility and, in particular, enable faster start-ups. On the other hand, they should ensure operating safety, i.e. thermal stresses in the main elements of the turbine and of the boiler must be kept within al lowable values during the start-up entire procedure. The issues related to optimization of the power unit operation have been the subject of many studies and scientific publications.

For example, the results of studies on optimization of the heating of the power boiler thick-walled elements are included in $[3,4]$. Optimal characteristics of steam temperature and pressure that enable fast start-ups of the boiler are presented in [5].

The results of studies on optimization of the heating of

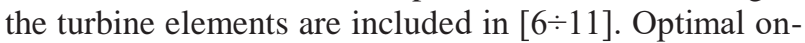
line control schemes of the steam inlet temperature taking account of low-cycle fatigue are presented in [6]. In [7], a genetic particle swarm optimization algorithm is used to find the best rates of raising steam temperature. Paper [8] focuses on integrating a steam accumulator into the power plant process to increase the power plant flexibility. Paper [9] adopts input and output data of a finite-element analysis under cold start-up conditions to establish an online damage-monitoring model of a steam turbine rotor. O ptimization of the start-up of a high-pressure rotor for a large-power steam turbine is discussed in [10]. Different cold start-up optimization schedules for a $320 \mathrm{MW}$ subcritical condensing steam turbine are made in [11]. The issues of turbine operation optimization described in literature are focused primarily on cold start-up optimization. The further part of this paper presents a discussion of problems related to the optimization of warm and hot start-ups, as start-ups from these thermal states will become dominant in the current operating conditions of power plants. An analysis is conducted of changes in thermal states in the turbine main elements 
after short downtime periods, and the possibilities and consequences of the turbine fast start-up from such states are demonstrated. The analyses make use of computer simulations of thermal and strength states in turbine elements performed by means of the finite element method. Numerical models of the turbine elements, as well as details of thermal and flow analyses and the selection of boundary conditions, are described e.g. in [12, $13]$.

\section{Optimization of the turbine warm start-up}

The turbine warm start-up optimization is more complex compared to start-ups from the cold state because such a process includes start-ups carried out after several or a few dozen hours of downtime. The thermal state of elements after such cooling times can be different. For this reason, the optimization procedure in the first step must include an analysis of the cooling of the turbine elements. Considering that even in a single power unit turbines may differ in a number of characteristics, such as design solutions, organization of the steam flow to the sealing areas or the quality of insulation, the cooling process can proceed in a different way. The analysis should provide curves illustrating temperature changes of the turbine individual elements as they cool. Determination of the temperature change is particularly important in inlet regions of the elements, rotors included, because when the turbine is re-started, these places will come into contact with steam entering the flow system. The temperature difference between steam and the element metal $\left(\Delta T_{s-m}\right)$ will have an impact on thermal stresses generated in this area. Therefore, temperature difference $\Delta T_{s-m}$ will be the first quantity to optimize. Since the manufacturer's start-up characteristics are broken lines it is assumed to maintain their shape and to change only the slopes. A nother reason is that linear change in parameters (mainly temperature) which means a constant temperature change ratio results in minimum stress within the heated element.

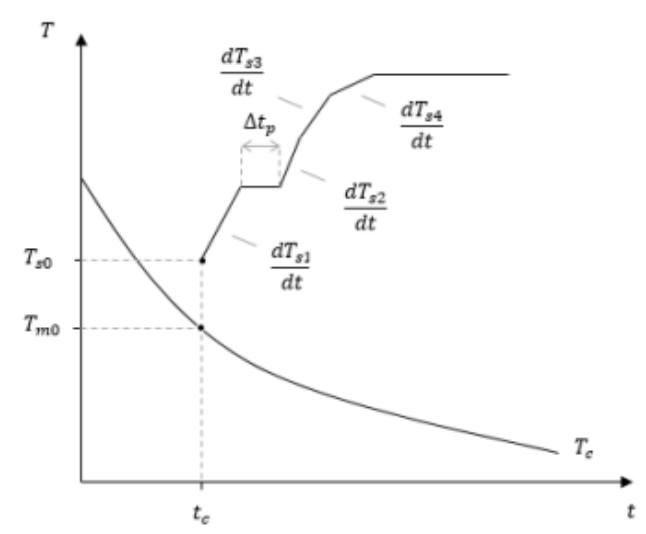

Fig. 2. Optimized quantities of the characteristic of the rotor heating from the warm state

So the other quantities optimized as the rotor is heated during start-ups from the warm state are derivatives (slopes) of the steam temperature change $d T_{s 1} / d t$, $d T_{s 2} / d t$ and $d T_{s 3} / d t$, as well as the time of the steam temperature stabilization $\Delta t_{p}$ (cf. Fig. 2). In the next step, curves illustrating changes in pressure, power and the rotor rotational speed are selected for the optimized temperature curve.

\subsection{Optimization of the turbine heating from the warm state after 36 hours of downtime}

The rotor heating process in a $200 \mathrm{M} \mathrm{W}$ turbine after 36 hours of downtime is discussed as an example of the selection of the optimal parameters of running start-ups from the warm state. The first stage consisted in computer simulations of the HP rotor cooling process. Example results of the analysis are presented in Fig. 3. In its top part, Fig. 3 shows the temperature distribution on the surface of the rotor central bore as cooling proceeds. The bottom part illustrates the distribution of temperature in the rotor after 36 hours of cooling.

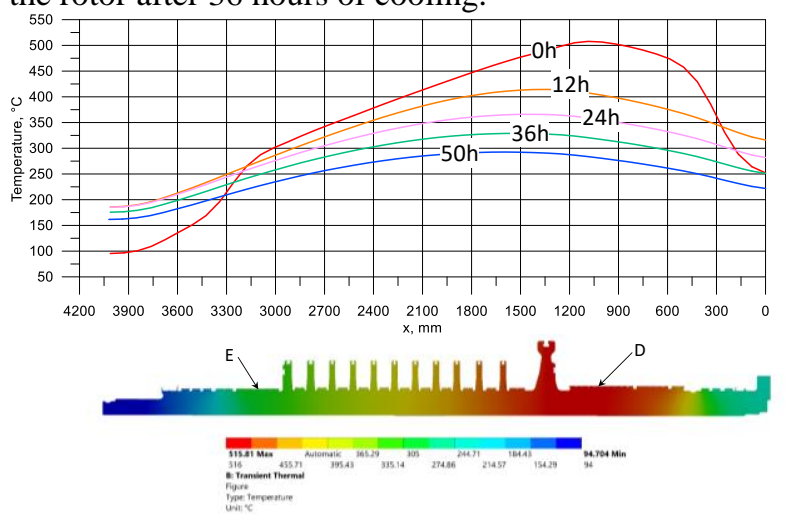

Fig. 3. Temperature field after 36 hours of the rotor cooling (bottom) and the temperature distribution on the central bore surface during the cooling process (top)

It can be seen that the heat is transferred from the hottest inlet part outbound in order to equalize the rotor temperature. How ever, the process is not very fast and one can observe that even after 50 hours of cooling there is still about 150K temperature difference within the element. W hat is more, the back part of the rotor is heated up within the first 12 hours by about $80 \mathrm{~K}$. It can result with enhanced stress at this area if too cold steam is introduced.

In the second stage, a heating curve was selected for this thermal state of the rotor that enables the rotor fastest heating without exceeding allowable values of maximum stresses. The allowable stress values, included in the range of 250-300 MPa depending on temperature, was established based on the results of small punch testing (SPT) of micro specimens [14] of the rotor material. The curve illustrating changes in live steam temperatures optimized for such conditions and the curves representing changes in pressure and in the rotor rotational speed are shown in Fig. 4. Time-dependent history of effective stresses in the sealing area, where the stresses reach maximum values, is shown in Fig. 5. 


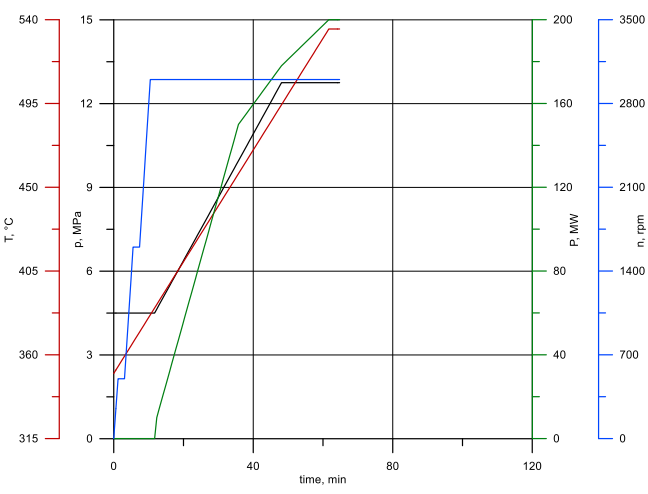

Fig. 4. Optimized history of changes in the turbine start-up parameters after 36 hours of cooling

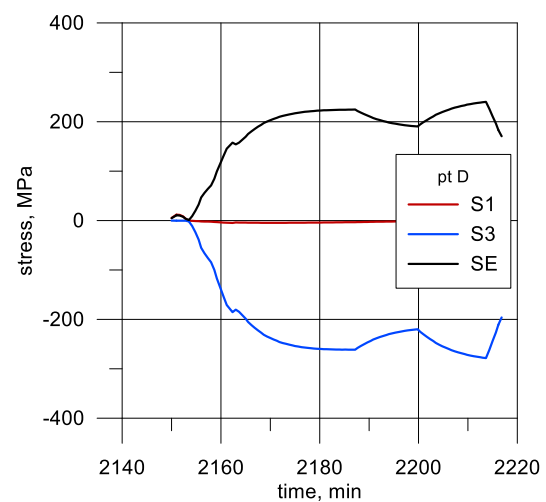

Fig. 5. Histories of stress components and equivalent (von $M$ ises) stresses in the rotor sealing area

The optimized start-up procedure results with maximum stress close to the limit value. One can see, that the element heating at the initial stage of start-up results in quite a rapid growth in stresses up to about $220 \mathrm{M} \mathrm{Pa}$ (von M ises) and then they stay at more less the constant level. This is the effect of a radial temperature gradient within the rotor. The higher the steammetal temperature difference the greater the resulting stress level. A fter the turbine reaches the nominal operation condition, the gradient changes direction to axial and the stress observed decrease (only the beginning of the process visible).

\section{Optimization of the turbine hot start- up}

The turbine hot start-up optimization process includes start-ups carried out after several or a few dozen hours of downtime. The thermal state of elements after such cooling times can be different. For this reason, the optimization procedure in the first step must include an analysis of the cooling of the turbine elements. The analysis should provide curves illustrating changes in the temperature of the turbine individual elements as they cool.

A detailed analysis of $200 \mathrm{M} \mathrm{W}$ turbine start-ups after a few hours of downtime indicates that the most common method is composed of two stages. Steam first flows through and heats the turbine IP part, and then it passes through the HP part. This fact is taken into consideration in the developed optimal start-up. The start-up model is presented in Fig. 6. Like in the case of warm start-ups, the process of cooling HP and IP rotors is modelled first. The change in the HP rotor maximum temperature is illustrated by curve $T_{C H P}$. Curve $T_{c I P}$ relates to the IP rotor. After time $t_{c I P}$, the start-up through the IP part begins, which is run according to the curve illustrating changes in the temperature of reheated steam and presented in Fig. 6.

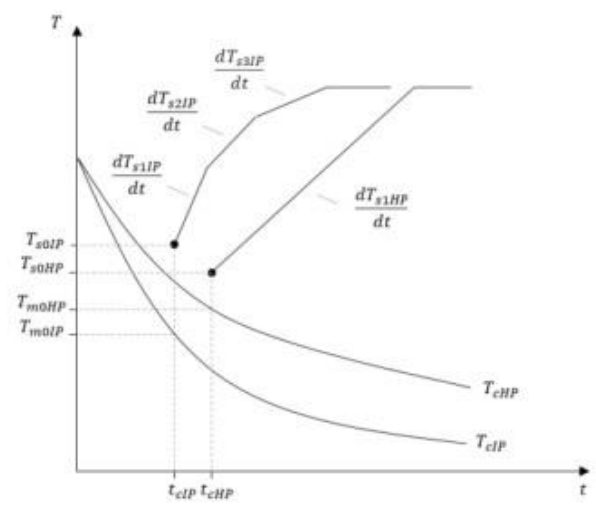

Fig. 6. O ptimized quantities of the hot start-up characteristic

The steam initial temperature $T_{\text {SOIP }}$ and the temperature gradients $\left(\frac{d T_{s 1 I P}}{d t}, \frac{T_{s 2 I P}}{d t}, \ldots, \frac{d T_{s n I P}}{d t}\right)$ are the optimized variables. A fter time $t_{c H P}$, steam begins to flow through the HP part. The steam initial temperature $T_{\text {SОНР }}$ and the temperature rise gradient $d T_{S 1 H P} / d t$ are the optimized quantities. After the optimal histories of changes in the temperature of steam flowing into the IP and the HP part are developed, the other curves are selected of changes in the steam pressure, the rotor revolutions and the turbine power.

\subsection{The turbine optimal hot start-up after 8 hours of downtime}

According to the optimization model discussed above, the turbine optimal start-up curves were developed for the thermal state after 8 hours of downtime. Using this procedure, the process of the cooling of the turbine elements was simulated. The time-dependent changes in the temperature of the HP and the IP rotor are presented in Fig. 7 and Fig. 8, respectively.

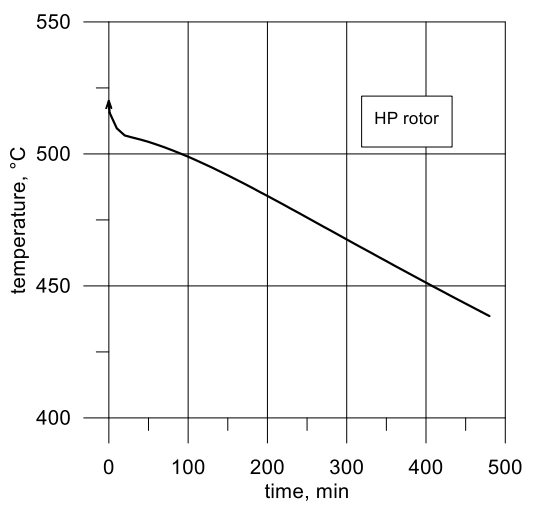

Fig. 7. Changes in the metal maximum temperature during the cooling of the HP rotor 


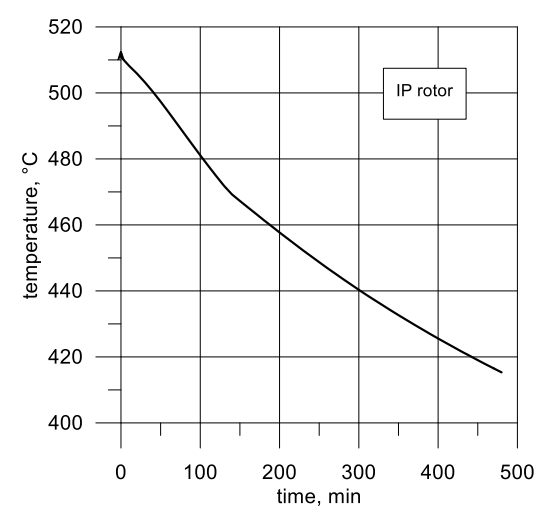

Fig. 8. Changes in the metal maximum temperature during the cooling of the IP rotor

The temperature distributions in the two rotors at the end of the 8-hour cooling process are shown in Figs. $9 \&$ 10. In the next step of the optimization procedure, the optimal curves illustrating the heating of the IP and the HP rotor were developed for these initial thermal states of the turbine main elements (curve Trs and curve Tls in Fig. 11).

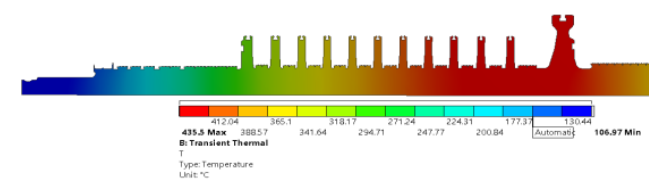

Fig. 9. Temperature field in the HP rotor at the beginning of the start-up procedure after 8 hours of cooling

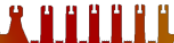

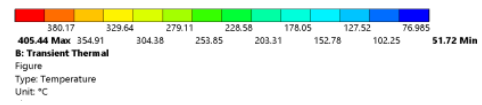

Fig. 10. Temperature field in the IP rotor at the beginning of the start-up procedure after 8 hours of cooling

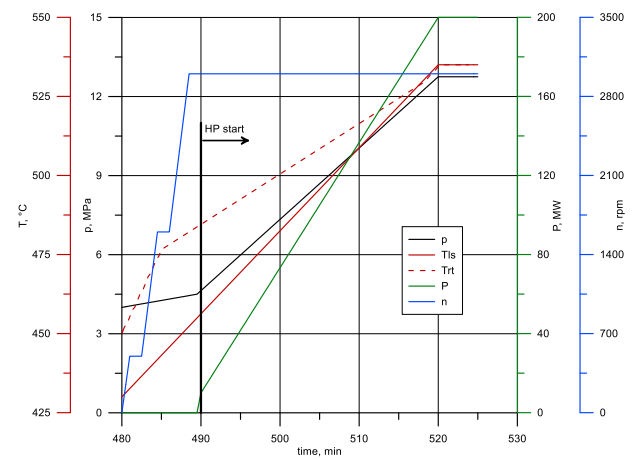

Fig. 11. Optimal changes in parameters during start-up

The HP start-up begins 10 minutes after the beginning of the start-up of the IP part and proceeds with a constant gradient. The reheated steam temperature changes along the 4-segment broken line, where the slopes differ by factor 5 . The entire optimized start-up characteristic is shown in Fig. 11. The stress states in the most loaded area of the IP rotor are presented in Fig. 12. The maximum values do not exceed $250 \mathrm{M} \mathrm{Pa}$. The histories of the values of stresses in the HP rotor are presented in Fig. 13 and Fig. 14. Fig. 13 shows the changes in stresses in the front sealing area whereas Fig. 14 - in the rear sealing area.

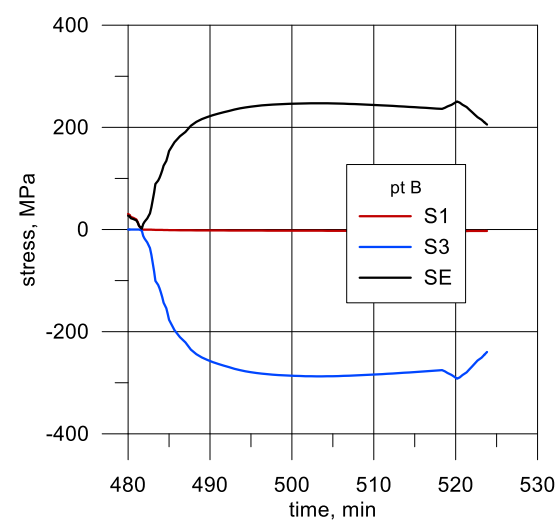

Fig. 12. Changes in maximum stresses in the IP rotor

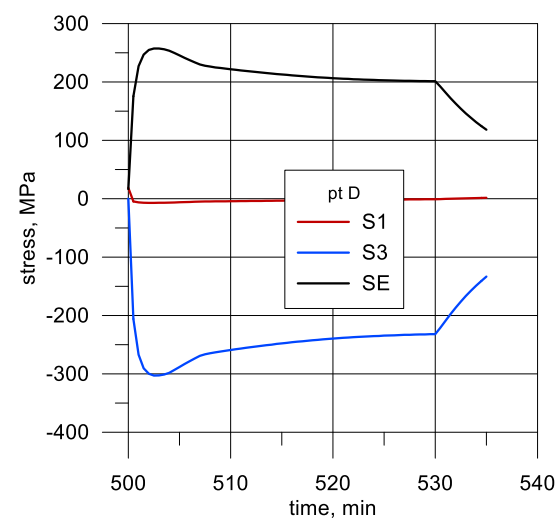

Fig. 13. Changes in stresses in the HP rotor front sealing area

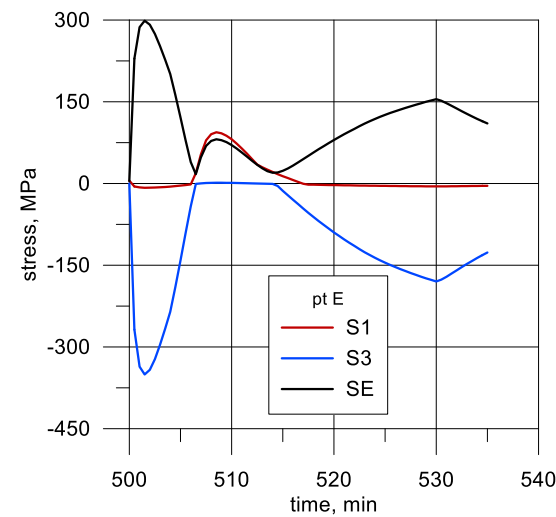

Fig. 14. Changes in stresses in the HP rotor rear sealing area

Similarly as in the case of warm start-up the most crucial stress magnitudes (objective variables) for both rotors growth rapidly to the assumed limit, and stay at more-less the same level till the nominal operating conditions are reached. Then stress tends to decrease to the steady-state magnitude. A bigger stress rise can be observed for a short time at the rear sealing, where hot steam (very small pressure drop in the turbine flow system at the beginning of the start-up) comes into contact with relatively cold rotor. Soon after, the turbine starts to produce power and steam expansion along the flow system becomes vital. The temperature at the rear sealing goes down, so as the stress level. 


\section{Conclusions}

The new conditions of the power system operation where priority is given to renewable energy sources impose the need to improve flexibility of the operation of the other sources of energy generation, including coalfired power units. It is therefore necessary to develop new methods of operation of both boilers and turbines in such units. The model of the turbine start-up optimization presented above indicates that the process of heating the turbine main elements can be accelerated safely, which means that it is possible to shorten the start-up time. The presented results concerning warm and hot start-ups suggest that it is possible to shorten the start-up time from $35 \%$ to as much as $45 \%$ compared to start-ups run according to the manufacturer $\odot$ characteristics. B oth the manufacturer@ start-up characteristics and the optimized characteristics discussed above should be treated as a reference standard that sets out the optimal method of the start-up process realization (i.e. the method of changing steam temperature and pressure and the rotor rotational speed) for a specific thermal state of the turbine elements and for the expected time of the start-up duration. As shown above, start-up characteristics which are correctly developed and suited to the turbine specific thermal state make it possible to shorten the time of the turbine start-up substantially, keeping the stress level below allowable values determined for each individual element.

\section{References}

1. Rusin, A., Wojaczek, A., 2015, Trends of changes in the power generation system structure and their impact on the system reliability, Energy, 92, pp. 128-134.

2. Lukowicz, H., Rusin, A., 2018, The impact of the control method of cyclic operation on the power unit efficiency and life, Energy, 150, pp. 565-574.

3. Taler, J., Węglowski, B., Taler, D., Sobota, T., Dzierwa, P., Trojan, M., M adejski, P., Pilarczyk, M., 2015, Determination of start-up curves for a boiler with natural circulation based on the analysis of stress distribution on critical pressure components, Energy, 92, pp. 153-159.

4. Taler, J., Węglowski, B., Zima, W., Grądziel, S., Zborowski, M., 1999, A nalysis of Thermal Stresses in a Boiler Drum During Start-up, Transactions of the ASME, J ournal of Pressure Vessel Technology, 121, pp. 84-93.

5. Taler, J., Dzierwa, P., Taler, D., Harchut, P., 2015, Optimization of the boiler start-up taking into account thermal stresses, Energy, 92 (1), pp. 160-170.

6. Zhang, H., Xie, D., Yu, Y., Yu, L., 2016, Online optimal control schemes of inlet steam temperature during start-up of steam turbines considering lowcycle fatigue, Energy, 117, pp. 105-115.

7. Ji, D., Sun, J., Sun, Q., Guo, H-C., Ren, J., 2018, Optimization of start-up scheduling and life assessment for a steam turbine, Energy, 160, pp. 1932.

8. Richter, M., Oeljeklaus, G., Gorner, K ., Improving the load flexibility of coal-fired power plants by the integration of a thermal energy storage, Applied Energy 236, 2019, pp. 607-621.

9. Sun, $Y-J ., L i u, X-Q ., H u, L-S ., T$ ang, $X-Y$.: O nline life estimation for steam turbine rotor, Journal of Loss Prevention in the Process Industries 26, 2013, pp. 272279.

10.Du, Q-W., Zheng, Z-L., Xie, Y-H., 2016, Optimization on start-up process of high-pressure rotor for large power steam turbine, Thermal Science, 20, pp. 815-822.

11.Ji ,D-M., Sun, J-Q., Dui, Y., Ren, J-X., 2017, The optimization of the start-up scheduling for a $320 \mathrm{M} \mathrm{W}$ steam turbine, Energy, 125, pp. 345-355.

12. Rusin, A., Łukowicz, H., Kosman, W., 2015, Transient Temperature and Thermal Stresses in Turbine Components, a chapter in: R. H etnarski (ed.), Encyclopaedia of Thermal Stresses, Springer Science, $\mathrm{N}$ etherlands.

13. Chmielniak, T., Nowak, G., Łukowicz, H., Rusin, A., 2017, A nalysis of Thermal and Stress States in Transient Operation of a Turbine Co-operating with Twinboiler, Heat Transfer Engineering, 39, (13-14), pp. 1251-1259.

14. Hähner, P., Soyarslan, C., Çakan, B., Bargmann, S., 2019, Determining Tensile Y ield Stresses from Small Punch Tests: A numerical-based scheme, M aterials \& Design, V olume 182, pp. 1-11 